\title{
Table of constitutions, legislation, and regulations
}

\section{CONSTITUTIONS}

India Const. art. $51 \mathrm{~A}(\mathrm{~g})$

U.S. Const. amend. IV $.72,86$ 110

\section{LEGISLATION}

\section{New Zealand}

Resource Management Act 1991

$$
\text { (N.Z.)... }
$$

Te Urewera Act 2014 .94

Te Awa Tupua (Whanganui River Claims Settlement) Bill 2016 (129-1) (N.Z.) 91

Town and Country Planning Act 1977 (N.Z).

Tūhoe Claims Settlement Act 2014 (N.Z) 94

Waikato-Tainui Raupatu Claims (Waikato River) Settlement Act 2010 (N.Z.) . .89

\section{United States}

Cal. Health \& Safety Code $§ 25982$ (West 2016) .244

Cal. Health \& Safety Code $\$ 25996$ (West 2016) .246

Cal. Penal Code $\S 599$ f (West 2016)..244

Cal. Water Code pt. 2.74 (West 2016) 82

Colo. Rev. Stat. Ann. § 40-2-127 (West 2016) .224

Conn. Gen Stat. § 21a-92c (2016) ....247

Consolidated Appropriations Act of 2016, Pub. L. No. 114-113, § 181, 129 Stat. 2242, 3073 (2015)
Energy Credit, 26 U.S.C. $§ 48$ (West 2015) 213

Jumpstart Our Business Startups (“JOBS") Act, Pub. L. No. 112-106, 126 Stat. 306 (2012) 168,177

Me. Rev. Stat. Ann. tit. 22, § 2593 (2016) .247

Pittsburgh, Pa., Code ch. 618, art. I, $\S 618.03$ (2010) ............................ 80

Public Utility Regulatory Policies Act, 16 U.S.C. $\$ \S 2601-2645$ (1978). 190

Residential Energy Efficient Property, 26 U.S.C. $§ 25 D$ (West 2015)

Santa Monica, CA, Municipal Code ch 4.75, § 4.75 .040 (2013) ... 82

Securities Act, 15 U.S.C. $\$ 77$ (2012). $172-173,175,178$

Securities Exchange Act, 15 U.S.C. $\S 78$ (2015) .......... 172-173, 175, 178

Vt. Stat. Ann. tit. 30, § 219a (2016). 206

Vt. Stat. Ann. tit. 9, § 3041 (2016) $247-248$

Vt. Stat. Ann. tit. 9, § 3044 (2016). .247

Wash. Rev. Code Ann. § 82.16.110 (West 2016) 224

\section{REGULATIONS}

17 C.F.R. $\S 230.504$ (b) (2016) ....... 167

17 C.F.R. $\$ 230.506$ (c) (2016) ........167

17 C.F.R. 230.147(c)(2) (2016)...... 176

17 C.F.R. 240.10b-5 (2016)........... 179

19417 CFR $\S 230.501$ (a) (2016) ......... 167 
Crowdfunding, 80 Fed. Reg. 71388 (Nov. 16, 2015)

Exec. Order No. 12,898, 3 C.F.R. § 859 (1995)

Exec. Order No. 13676, 3 C.F.R. § 217 (2015)

Promoting Wholesale Competition

Through Open Access Non-

Discriminatory Transmission

Services by Public Utilities;

Recovery of Stranded Costs by

Public Utilities and Transmitting

Utilities, Order No. 888, 61 FR

21540 (May 10, 1996), 18 C.F.R.

pts. 35,385 (2015)
Proposed Revision of Certain Exemptions from the Registration Provisions of the Securities Act of 1933 for Transactions Involving Limited Offers and Sales, 46 Fed. Reg. 41,791 (1981).

\section{OTHER AUTHORITIES}

Framework Convention on Climate Change, Paris Agreement, U.N. Doc. FCCC/CP/2015/L.9 (Dec. 12, 2015) 